https://helda.helsinki.fi

\title{
Vitamin C, neutrophils and the symptoms of the common cold : [Letter]
}

\section{Hemilä, Harri}

1992

Hemilä , H 1992 , ' Vitamin C, neutrophils and the symptoms of the common cold : [Letter] ' ,

Pediatric Infectious Disease Journal, vol. 11 , no. 9 , pp. 779-779 . https://doi.org/10.1097/00006454-199209000-00

http://hdl.handle.net/10138/225869

https://doi.org/10.1097/00006454-199209000-00029

publishedVersion

Downloaded from Helda, University of Helsinki institutional repository.

This is an electronic reprint of the original article.

This reprint may differ from the original in pagination and typographic detail.

Please cite the original version. 
5. Dunn V. Bale JF. Zimmerman RA, et al. MRI in children with postinfections disseminated encephalomyelitis. Magnetic Resonance Imaging 1986;4:25-32.

6. Marks NA, Bodensteiner JB, Bobele GB, et al. Parainflammatory leukoencephalomyelitis: clinical and magnetic resonance imaging findings. J Child Neurol 1988;3:205-13.

\section{VITAMIN C, NEUTROPHILS AND THE SYMPTOMS OF THE COMMON COLD}

\section{To The Editors:}

The pathogenesis of common cold infection is not wellunderstood. Apparently the viral infection per se is not the principal reason for the symptoms. For example a rhinovirus infection does not produce detectable cytopathic effects on a monolayer culture of nasal epithelial cells. ${ }^{1}$ Instead it has been suggested that exaggerated host responses may play a crucial role in the pathogenesis. Neutrophils infiltrate the nasal mucosa early in the course of infection, ${ }^{2}$ and there is a significant correlation between the number of neutrophils in the nasal lavages and the severity of symptoms of rhinovirus infection. ${ }^{3}$ In general immunocomplexes are efficient activators of neutrophil respiratory burst (the production of superoxide and other oxidants derived thereof). For example the respiratory syncytial virus-antibody complex activates the respiratory burst of neutrophils, and it has been suggested that the released oxidants may play a role in the pathogenesis of the respiratory syncytial virus infection. ${ }^{4}$

If the generation of oxidants by neutrophils is a partial cause of the symptoms of an infection, then the symptoms should be ameliorated by decreasing the steady state oxidant levels. In fact this has been observed in mice infected with influenza virus. ${ }^{5}$ Superoxide production by phagocytes was increased severalfold by the infection. It is noteworthy that the mortality caused by influenza was significantly decreased in mice injected with superoxide dismutase, a superoxide-degrading enzyme. Accordingly the oxygen radicals may have a role in respiratory virus infections in vivo, even though one must be prudent when extrapolating characteristics of the human common cold from those of influenza in mice.

Vitamin $\mathrm{C}$ is a major antioxidant in human plasma ${ }^{6}$; therefore it may be an important physiologic factor in counteracting the oxidants released by the neutrophils. Activation of neutrophils in vitro causes rapid oxidation of extracellular vitamin $C$, which suggests that high concentrations of the vitamin should provide protection against the damage caused by the oxidants released in vivo. ${ }^{7}$ If oxidants produced by neutrophils play a role in the pathogenesis of the common cold, then one would expect that (1) vitamin $C$ metabolism changes during the common cold and (2) vitamin $\mathrm{C}$ supplementation ameliorates the symptoms of the common cold.

During a common cold the vitamin $\mathrm{C}$ concentration in leukocytes and the amount of the vitamin excreted in urine decreases. ${ }^{8}$ Moreover although large intakes (4 to $10 \mathrm{~g} /$ day) of vitamin $\mathrm{C}$ typically cause stomach ailments such as diarrhea among healthy people, persons who have caught a common cold may ingest over $30 \mathrm{~g} /$ day without apparent overdosage problems. ${ }^{9}$ This variation is further evidence of changes in vitamin $\mathrm{C}$ metabolism in people infected with common cold viruses.

Regarding the second point about 20 double blind studies have consistently shown that vitamin $\mathrm{C}$ decreases the duration or severity of common cold episodes. ${ }^{8}$ Although vitamin C participates in several other reactions in the body, in addition to the antioxidant reactions, none of the other reactions appears to be a likely explanation for the amelio- ration of symptoms. ${ }^{8}$ Accordingly the results of the intervention studies with vitamin $C$ are consistent with the hypothesis that neutrophil activation is partially responsible for the symptoms of the common cold.

The precise clinical significance of the role of vitamin $\mathrm{C}$ in the common cold cannot be clearly inferred from the studies conducted, since a large variation has been observed in the beneficial effects of the vitamin. ${ }^{8}$ On the other hand there are some data to suggest that more benefit could be obtained from vitamin $\mathrm{C}$ doses higher than those used in the controlled studies. ${ }^{8,9}$

Apparently various viral and bacterial infections may lead to the activation of neutrophils; thus the potential uses of vitamin $\mathrm{C}$ should not be limited to the common cold. Several studies have indicated that vitamin $\mathrm{C}$ may also ameliorate the symptoms of various viral and bacterial infections (for a review see Reference 10). However, these studies are 30 to 60 years old ${ }^{10}$ and there seem to be no recent, thorough studies on infections other than those of the common cold viruses. Still it has quite recently been suggested that large amounts of vitamin $\mathrm{C}$ may be beneficial for patients with bacterial infections. ${ }^{9}$

Obviously the role of vitamin $\mathrm{C}$ in infections should be studies in more detail. The common cold studies indicate that prevention of scurvy is not the sole physiologic role of vitamin C. Furthermore in several disease conditions, such $\therefore$ the common cold, the level of intake of the vitamin derived from a normal diet may be insufficient for the best functioning of the body.

Harri Hemilä, Ph.D. Department of Public Health University of Helsinki Helsinki, Finland

Accepted for publication May 20, 1992.

Key words: Vitamin C, neutrophils, common cold.

1. Winther B, Gwaltney JM, Hendley JO. Respiratory virus infection of monolayer cultures of human nasal epithelial cells. Am Rev Respir Dis 1990;141:839-45.

2. Turner RB. The role of neutrophils in the pathogenesis of rhinovirus infections. Pediatr Infect Dis J 1990;9:832-5.

3. Naclerio RM, Proud D, Lichtenstein LM, et al. Kinins are generated during experimental rhinovirus colds. J Infect Dis 1988;157:133-42.

4. Faden H, Kaul TN, Ogra PL. Activation of oxidative and arachidonic acid metabolism in neutrophils by respiratory syncytial virus antibody complexes: possible role in disease. J Infect Dis 1983;148:110-6.

5. Maeda H, Akaike T. Oxygen free radicals as pathogenic molecules in viral diseases. Proc Soc Exp Biol Med 1991;198:721-7.

6. Halliwell B, Gutteridge JMC. The antioxidants of human extracellular fluids. Arch Biochem Biophys 1990;280:1-8.

7. Hemilä H, Roberts $\mathrm{P}$, Wikström $\mathrm{M}$. Activated polymorphonuclear leucocytes consume vitamin C. FEBS Lett 1984;178: 25-30.

8. Hemilä H. Vitamin C and the common cold. Br J Nutr 1992; 67:3-16.

9. Cathcart RF. Vitamin C, titrating to bowel tolerance, anascorbemia, and acute induced scurvy. Med Hypotheses 1981;7: 1359-76.

10. Stone I. The healing factor: vitamin $\mathrm{C}$ against disease. New York: Grosset and Dunlap, 1972.

\section{DECLINE OF HAEMOPHILUS DISEASE IN CLEVELAND}

To The Editors:

The original vaccine for Haemophilus influenzae type $b$ (Hib) consisted of the purified polysaccharide capsule 